\title{
Postpartum Psychiatric disorders -A neglected Issue
}

\section{Ameelia Sadaqat ${ }^{1}$, Rabia Afzal ${ }^{2}$, Nauman Mazhar ${ }^{3}$, Naila Mairaj ${ }^{4}$, Sadaf Malik ${ }^{5}$, Aysha Butt $^{6}$}

\begin{abstract}
Objective: To find out psychiatric morbidity among females presenting during postpartum period at a tertiary care hospital in Lahore.

Methods: A cross-sectional study was done in Department of Obstetrics and Gynaecology of Central Park Teaching Hospital, Lahore. One Hundred women presenting in peripartum period were included in the study, using purposive sampling technique. After an informed consent participant's bio data was recorded. A structured proforma was used for psychiatric evaluation of the cases, which contained social and demographic details along with questions from Edinburgh postnatal depression scale. Psychiatric diagnosis was made according to DSM-5. Severity of illness was assessed using Hamilton rating scale for depression and Hamilton anxiety rating scale.

Results: Postpartum follow up of 100 females revealed that $18 \%$ developed psychiatric morbidity. 13 had major depressive disorder and 5 females had anxiety disorder. There was no case of puerperal psychosis in any of the females postpartum in this study. Psychiatric morbidity and age group between 18-25 years $(20.6 \%)$ showed significant correlation. Similarly, higher incidence of psychiatric morbidity was observed in women living in nuclear household (24.1\%).

Conclusion: Psychiatric morbidities are common among females during postpartum period. Major depression is the commonest one. Therefore assessment for depression should be included in routine obstetric follow-ups.

Key Words: psychiatric morbidity, major depression, anxiety disorder, puerperal psychosis, postpartum females.
\end{abstract}

\section{Introduction}

$\mathrm{C}$ hildbirth brings multiple challenges to the mother, e.g. loss of sleep, emotional and physical trauma, initiation of breast feeding, adjustment with life relationships and socially isolated routine. How-ever, bonding with the newborn is the most important psychological process. Postpartum period along with pregnancy are

\begin{tabular}{|c|c|}
\hline 1. Ameelia Sadaqat & 2. Rabia Afzal \\
\hline 3. Nauman Mazhar & 4. Naila Mairaj \\
\hline 5. Sadaf Malik & 6. Aysha Butt \\
\hline \multirow{6}{*}{\multicolumn{2}{|c|}{$\begin{array}{l}\text { 1. Department of Obstetrics \& Gynaecology, Lahore Medical \& Dental } \\
\text { College } \\
\text { 2. Department of Obstetrics \& Gynaecology, Allied Hospital Faisalabad } \\
\text { 3. Department of Psychiatry \& Behavioral Sciences, Services Institute of } \\
\text { Medical Sciences/Services Hospital Lahore. } \\
\text { 4. Obs \& Gynae, Ghurki Trust Teaching Hospital } \\
\text { 5. Shareef Medical \& Dental College } \\
\text { 6. Department of Psychiatry \& Behavioral Sciences. Services Institute of } \\
\text { Medical Sciences/Services Hospital Lahore }\end{array}$}} \\
\hline & \\
\hline & \\
\hline & \\
\hline & \\
\hline & \\
\hline \multicolumn{2}{|l|}{ Correspondence: } \\
\hline \multicolumn{2}{|c|}{$\begin{array}{l}\text { Dr Ameelia Sadaqat, Associate Professor, Department of Gynae and Obst. } \\
\text { Lahore Medical and Dental College } \\
\text { E-mail: ameeliasadaqat@gmail.com }\end{array}$} \\
\hline & \\
\hline $\begin{array}{l}\text { Subm } \\
1 \text { st } R\end{array}$ & \\
\hline Acceptance Date: & $04-11-2020$ \\
\hline
\end{tabular}

considered to be emotionally and psy-chologically vulnerable periods. ${ }^{1}$ In many instances, childbirth brings joy in the family, but it could be a stressful event for a few women, severe enough to provoke a mental breakdown. ${ }^{2}$ The association bet-ween emotional or psychiatric disorders and postpar-tum period has been documented since Hippocratic times. ${ }^{3}$

The placenta is an endocrine organ of fetal origin and dysregulation of placental corticotropin releasing hormone(CRH) may play a role in development of postpartum depression ${ }^{4}$. Many studies show that a woman has an increased risk of admission in a psychiatric ward of hospital within the first month after childbirth than any other time ${ }^{5,6}$. Around $12.5 \%$ of women admission in a psychiatric ward occur generally during the postpartum time period ${ }^{7}$.

Postpartum mental disorders are generally divided into three broad categories, i.e. non psychotic postpartum depression, puerperal psychosis and postpartum blues. All three of these have distinct clinical 
features but affect female population in all social classes and have not been associated with any biological or psychological variable.

Postpartum blues manifest as mild depressive symptoms that develop within 2-3 days of delivery and are self-limiting that resolve within 2 weeks of onset of symptoms. Postpartum blues develop in around 50\% of the females but the pathogenesis is unknown. ${ }^{8-11}$ Postnatal decrease in estrogen level which increases the level of monoamine oxidase A (enzyme) can be one of the factors. ${ }^{12}$ Women with postpartum blues have 4-11 times greater risk of developing postpartum major depression and 4 times increased risk of anxiety disorder. ${ }^{9}$ Symptoms include low mood, crying, anxious behavior, irritability, insomnia, exhaustion and loss of concentration. Postpartum blues is not recognized as a diagnostic entity by American Psychiatric Association's Diagnostic and Statistical Manual. ${ }^{13}$ Thus, it just represents as a prodromal phase of depressive and anxiety syndromes.

The etiology of postpartum depression is a complex interaction of psychological, social and biological factors, in addition to genetic and environmental factors. Maternal sensitivity, attachment with the newborn and style of parenting is essential for a healthy development of an infant's cognitive and behavioral skills. Mothers who are depressed display less attachment with the infant and harsh parenting style. This results in adverse outcomes in child's development. A retrospective study of women with postpartum onset of major depression found that in $54 \%$ cases onset of PPD was within 4 weeks postpartum. ${ }^{14}$ The most consistent risk factor, which has the largest effect, is past history of either perinatal or nonperinatal depression. ${ }^{15}$

The clinical picture of postpartum psychosis includes hallucinations and delusions, abnormal behavior, disorientation and delirium. Postpartum psychosis is a medical emergency and requires immediate hospitalization, along with comprehensive psychiatric evaluation and medical management.

\section{Methods}

The study was conducted in the Department of Obstetrics \& Gynaecology of Central Park Teaching Hospital affiliated with Central Park Medical College, Lahore. Hundred women were included in the study. They were admitted for delivery either from OPD or Emergency after screening for fulfillment of criteria of inclusion. All participants were explained the nature and purpose of study and a written informed consent was obtained. The study was ethically approved by Institutional review board of Central Park Teaching hospital. Women less than 18 years of age and above 40 years, females having any associated systemic disease and mental disorder were excluded from the study. Cases with intrauterine fetal death were also not included in the study. All females were evaluated on first postnatal day, at 2 weeks' time period and afterwards at 4 weeks postpartum. A structured proforma containing social and demographic details was used to enter the basic details of the participants. Psychiatric evaluation was done on the basis of information collected on the above mentioned proforma and questions from Edinburgh postnatal depression scale. ${ }^{16}$ Psychiatric diagnosis was made according to DSM-5. Severity of illness was assessed using Hamilton rating scale for depression ${ }^{17}$ and Hamilton anxiety rating scale. ${ }^{18}$

\section{Results}

$63 \%$ of females were in the age range of $18-25$ years, followed by $20 \%$ in the age range of 26-33 years and $17 \%$ in $34-40$ years. Majority of the females were illiterate i.e. $55 \%$. $27 \%$ had received primary education whereas $12 \%$ had completed secondary education and only $6 \%$ of them were graduates. Out of all the women $73 \%$ were housewives and the rest of $27 \%$ were working women. $53 \%$ belonged to semi-urban society and $25 \%$ were from rural background. $22 \%$ of women belonged to urban background. Majority of women $(75 \%)$ belonged to lower socioeconomic class as our hospital is a charity hospital catering to the needs of surrounding village population. 18\% belonged to middle class and only $7 \%$ belonged to upper class. $71 \%$ of the females lived in a joint family set with good family support and $29 \%$ lived as a nuclear family.

Out of the 100 females 64 were multipara and 36 were primipara. As far as mode of delivery is concerned out of the 100 deliveries 58 were normal vaginal deliveries and 42 were lower segment cesarean sections. There were 97 singleton births and 3 twin deliveries. Out of the 97 singleton births 38 women gave birth to male babies and there were 59 births of female babies. 
Postpartum follow up of 100 females revealed that 18 developed psychiatric morbidity. 13 had major depressive disorder and 5 females had anxiety disorder. There was no case of puerperal psychosis in any of the postpartum females.

Table 1: Socio-Demographic Profile

\begin{tabular}{|c|c|c|c|}
\hline \multicolumn{2}{|c|}{ Variables } & \multirow{2}{*}{$\begin{array}{c}\begin{array}{c}\% \\
\mathbf{N}\end{array} \\
(\mathrm{N}=\mathbf{1 0 0})\end{array}$} & \multirow{2}{*}{$\begin{array}{c}\begin{array}{c}\text { Psychiatric } \\
\text { morbidity N(\%) }\end{array} \\
13(20.6)\end{array}$} \\
\hline Age(years) & $18-25$ & & \\
\hline & $26-33$ & 20 & 03 (15) \\
\hline & $34-40$ & 17 & 02 (11.7) \\
\hline \multirow[t]{4}{*}{ Education } & Illiterate & 55 & $10(18.1)$ \\
\hline & Primary & 27 & $06(22.2)$ \\
\hline & Secondary & 12 & $02(16.6)$ \\
\hline & Graduate & 6 & \\
\hline \multirow[t]{2}{*}{ Occupation } & Housewife & 73 & $14(19.1)$ \\
\hline & Working & 27 & $04(14.8)$ \\
\hline \multirow[t]{3}{*}{ Residence } & Urban & 22 & $03(13.6)$ \\
\hline & Semi-urban & 53 & $12(22.6)$ \\
\hline & Rural & 25 & $03(12)$ \\
\hline \multirow[t]{3}{*}{ Economic status } & Upper & 7 & $01(14.1)$ \\
\hline & Middle & 18 & $02(11.1)$ \\
\hline & Lower & 75 & $15(20)$ \\
\hline \multirow[t]{2}{*}{ Type of Family } & Nuclear & 29 & $07(24.1)$ \\
\hline & Joint & 71 & $11(15.4)$ \\
\hline
\end{tabular}

Among the 13 females diagnosed with major depressive disorder $46.1 \%$ had mild depression, $30.7 \%$ had moderate depression, $15.3 \%$ had severe depression and $7.6 \%$ had very severe depression according to Hamilton rating scale for depression (HRSD). In anxiety disorder group out of 5 women $4(80 \%)$ had moderate anxiety and $1(20 \%)$ had severe anxiety.

Psychiatric morbidity and age group between 18-25 years $(20.6 \%)$ showed significant correlation. Similarly, higher incidence of psychiatric morbidity was observed in women living in nuclear household (24.1\%). There was no correlation between education of women, their dwelling whether rural, urban or semi-urban and economic status with psychological status. Multiparity had significant correlation (18.7 $\%$ with development of postpartum psychiatric disorders and same is the observation in case of cesarean delivery (23.8\%). Postpartum depression was seen in $23.7 \%$ of women who gave birth to female babies.

\section{Discussion:}

This study was aimed to investigate that how females without any past psychiatric history develop psychia- tric illness. This ruled out the major known determinant of development of postpartum psychiatric morbidity i.e. past history ${ }^{19}$ and let us get an insight of other risk factors.

One of the most challenging aspects of postpartum depression is that how affected population remains undetected. Mothers try to hide their feelings because of the social stigma attached with psychiatric disor-

Table 2: Obstetric Profile

\begin{tabular}{|llcc}
\hline \multicolumn{2}{c}{ Variable } & $\begin{array}{c}\text { \% } \\
(\mathbf{N = 1 0 0 )}\end{array}$ & $\begin{array}{c}\text { Psychiatric } \\
\text { morbidity(\%) }\end{array}$ \\
\hline Parity & Primipara & 36 & $06(16.6)$ \\
Mode of delivery & Multipara & 64 & $12(18.7)$ \\
& Vaginal & 58 & $08(13.7)$ \\
& Cesarean & 42 & $10(23.8)$ \\
Babies born & Male & 38 & $04(10.5)$ \\
& Female & 59 & $14(23.7)$ \\
& Twins & 3 & 0 \\
\hline
\end{tabular}

Table 3: Distribution of Psychiatric Morbidity

\begin{tabular}{lclcc}
\hline \multicolumn{1}{c}{$\begin{array}{c}\text { Psychiatric } \\
\text { morbidity }\end{array}$} & $\begin{array}{c}\text { \% } \\
(\mathbf{N = 1 0 0 )}\end{array}$ & Severity & $\begin{array}{c}\text { No } \\
\text { cases }\end{array}$ & Score \\
\hline $\begin{array}{l}\text { Major depressive } \\
\text { disorder }\end{array}$ & 13 & Mild & 6 & $8-13$ \\
& & Moderate & 4 & $14-18$ \\
& & Severe & 2 & $19-22$ \\
Anxiety disorder & 5 & Very Severe & 1 & $>23$ \\
& & Soderate & 4 & $18-24$ \\
No Psychiatric & 82 & & 1 & $>25$ \\
morbidity & & & & \\
\hline
\end{tabular}

ders. These mood disorders can have devastating effects on mothers as well as the newborn.

Risk factors that are frequently associated with postpartum depression are poor social and financial support, ${ }^{20}$ age $<25$ years, multiparity, intimate partner violence, poor perinatal physical health. ${ }^{21}$ Psychiatric illness was observed in almost $18 \%$ of the females in their postpartum period during follow up. Out of these, $13 \%$ were diagnosed as having major depressive disorder and rest had anxiety disorder. Ramchandani et al and Wan et al have reported prevalence of postpartum mood disorders as $16.4 \%$ and $15.5 \%$ respectively. ${ }^{22,23}$ Britton along with his colleagues reported prevalence of anxiety as $24.9 \%$ during postpartum period out of which only one percent had diagnosis of severe anxiety. ${ }^{24}$

In our study majority (63\%)of females were in the age range of 18-25 years and the incidence of psychiatric morbidity was highest (20.6\%)in this age group as 
compared to $15 \%$ in the age range of $26-33$ years and $11.7 \%$ in age range of $34-40$ years. In the 73 housewives $19.1 \%$ developed psychiatric morbidity as compared to $14.8 \%$ in working women. A prospective cohort study conducted in University of Washington School of Medicine including 1423 pregnant women showed that women with postpartum depression were significantly younger $(\mathrm{p}<0.0001)$ and more likely to be unemployed $(p=0.04)^{25}$.

Our study showed psychiatric morbidity of $20 \%$ in women belonging to lower socioeconomic group in comparison to $14.1 \%$ and $11.1 \%$ in upper and middle socioeconomic group respectively. A Chinese survey revealed that postpartum depression was more common in low income group. ${ }^{22}$

Our study exhibited an increased risk of postpartum psychiatric disorders in multiparous (18.7\%) women in comparison to primiparous women( $16.6 \%)$.It was also found that psychiatric morbidity was $23.8 \%$ in case of cesarean delivery as compared to $13.7 \%$ in the vaginal delivery group. Sword et $\mathrm{al}^{26}{ }^{26}$ also deduced in their prospective cohort study that multiparity has strong correlation (OR 1.59; 95\% CI 1.22-2.08)with postpartum psychiatric morbidity, but mode of delivery was not found to be independently associated with postpartum depression in their study. Contrarily Irfan and $\operatorname{Badar}^{27}$ reported that major proportion of females developing mental illness were primiparous. Amr and Balaha reported that $22.6 \%$ of the study population who delivered via cesarean section were having psychiatric illnesses. ${ }^{28}$

Further research is needed to understand these mythical morbidities, as still there is a lot to understand as to why and how are psychiatric disorders so closely related to pregnancy and postpartum period.

\section{Author's Contribution}

AS: Conception of study, literature search, data analysis, drafting of manuscript, revision, writing

RA: Data processing, interpretation

NM: Data analysis, interpretation, clinical manuscript revision and final draft

NM: Data collection and manuscript and revision

AB: Literature search, clinical manuscript

\section{References}

1. Cox JL, Murray D, Chapman G. A controlled study of the onset, duration and prevalence of postnatal depre- ssion. Br J Psychiatry. 1993;163:27-31.

2. Nonacs RM, Cohen LS. Postpartum psychiatric syndromes. In: Sadock BJ, Sadock VA, editors. Kaplan \& Sadock's comprehensive textbook of psychiatry. $7^{\text {th }}$ ed. New York: Lippincott Williams and Wilkinson; 2000. p. 1276-83.

3. Miller LJ. Postpartum depression. JAMA. 2002; 287 : 762-5.

4. Yim IS, Glynn LM, Dunkel-Schetter C, et al. Risk of postpartum depressive symptoms with elevated corticotropin-releasing hormone in human pregnancy. Arch Gen Psychiatry 2009; 66: 162.

5. Kendell RE, Chalmers JC, Platz C. Epidemiology of puerperal psychoses. Br J Psychiatry. 1987;150:66273.

6. Paffenbarger RS. Epidemiological aspects of mental illness associated with childbearing. In: Brockington IF, Kumar R, editors. Motherhood and mental illness. London: Academic Press; 1982.p. 21-36.

7. Duffy CL. Postpartum depression: identifying women at risk. Genesis. 1983;11:21.

8. Howard LM, Molyneaux E, Dennis CL, Rochat T, Stein A, Milgrom J.Non-psychotic mental disorders in the perinatal period. Lancet. 2014 Nov;384(9956): 1775-88. Epub 2014 Nov 14.

9. Reck C, Stehle E, Reinig K, Mundt C. Maternity blues as predictor of DSM-IV depression and anxiety disorders in the first three months postpartum. J Affect Disord. 2009;113(1-2):77. Epub 2008 June 24.

10. Gonidakis F, Christodoulou GN. Maternity blues in Athens, Greece: a study during first three days after delivery. J Affect Disord. 2007;99(1-3):107. Epub 2006 Sep 29.

11. Miller LJ. Postpartum depression. JAMA. 2002; 287(6): 762.

12. Sacher J, Wilson AA, Houle S, Rusjan P, Hassan S, Bloomfield PM, Stewart DE, Meyer JH.Elevated monoamine oxidase A binding in early postpartum period. Arch Gen Psychiatry. 2010;67(5):468.

13. American Psychiatric Association. Diagnostic and Statistical Manual of Mental Disorders, Fifth Edition (DSM-5), American Psychiatric Association, Arlington, VA 2013.

14. Altemus M, Neeb CC, Davis A, Occhiogrosso M, Nguyen T, Bleiberg KL. Phenotypic differences between pregnancy onset and postpartum-onset major depressive disorder. J Clin Psychiatry. 2012 Dec;73(12):e1485-91.

15. Patton GC, Romaniuk H, Spry E, et al. Prediction of perinatal depression from adolescence and before 
conception (VIHCS): 20-year prospective cohort study. Lancet 2015;386:875.

16. Cox JL, Holden JM, Sagovsky R. Detection of postnatal depression. Development of th 10-item Edinburgh Postnatal Depression Scale. Br J Psychiatry. 1987; 150:782.

17. Hamilton M. A rating scale for depression. J Neurol Neurosurg Psychiatry. 1960;23:56-62.

18. Hamilton M. The assessment of anxiety states by rating. Br J Med Psychol. 1959;32:50-5.

19. Parker GB, Hegarty B, Paterson A, et al. Predictors of post-natal depression are shaped distinctly by the measure of 'depression'. J Affect Disord 2015; 173: 239.

20. Nelson DB, Freeman MP, Johnson NL, et al. A prospective study of postpartum depression in 17648 parturients. J Matern Fetal Neonatal Med 2013; 26: 1155.

21. Abajobir AA, Maravilla JC, Alati R, Najman JM. A systematic review and meta-analysis of the association between unintended pregnancy and perinatal depression. J Affect Disord 2016; 192:56.

22. Wan EY, Moyer CA, Harlow SD, Fan Z, Jie Y, Yang H. Postpartum depression and traditional postpartum care in China: role of zuoyuezi. Int $\mathrm{J}$ Gynaecol Obstet. 2009;104:209-13.

23. Ramchandani PG, Richter LM, Stein A, Norris SA. Predictors of postnatal depression in an urban South African cohort. J Affect Disord. 2009;113:279-84.

24. Amr MA, Hussein Balaha MH. Minor psychiatric morbidity in young Saudi mothers using Mini International Neuropsychiatric Interview (MINI). J Coll Physicians Surg Pak. 2010;20:680-4.

25. Katon W, Russo J, Gavin A. Predictors of postpartum depression. J Womens Health (Larchmt) 2014; 23: 753.

26. Sword W, Landy CK, Thabane L, et al. Is mode of delivery associated with postpartum depression at 6 weeks: a prospective cohort study. BJOG 2011; 118: 966.

27. Irfan N, Badar A. Determinants and pattern of postpartum psychological disorders in Hazara division of Pakistan. J Ayub Med Coll Abbottabad. 2003;15:1923.

28. Amr MA, Hussein Balaha MH. Minor psychiatric morbidity in young Saudi mothers using Mini International Neuropsychiatric Interview (MINI). J Coll Physicians Surg Pak. 2010;20:680-4. 